\title{
Effects of Noodle Product Advertisements on Advertising Attitude and Purchase Intention of College Students
}

\author{
Joon-Ho Lee ${ }^{1}$, Sang-Hyun Hwang ${ }^{2}$ \\ ${ }^{l}$ Professor, Department of Communication \& Media, Dong-eui University, Korea, joonlee@deu.ac.kr \\ ${ }^{2}$ Assistant Professor, Department of Advertising \& PR, Dong-eui University, Korea, moca@deu.ac.kr \\ Corresponding author: Joon-Ho Lee
}

\begin{abstract}
This study is aimed to examine the effects of smartphone advertisements for a noodle product by exploring relationships between its traits and user's purchase intention of the product. Specifically, the study analyzed causal relationships among the types of the mobile advertisement, user's perception and attitude toward the advertising messages, and the user's subsequent intention to purchase. A series of experiments were conducted using a sample of 280 college students which were randomly divided into 4 groups and 3 of them were exposed to different types of advertisements. The following results and implications were found after the analysis using ANOVAs and linear multiple regressions. First, text/banner type is most effective in positively perceiving most traits of advertising. Second, immersion is the most significant factor in generating a higher advertising preference for video, text/banner, and $\mathrm{QR} /$ promotion advertisements. Third, informativeness is the most important factor affecting purchase intention of the groups exposed to video and text/banner advertisements. Also, customization and convenience are significant factors for purchase intention of those who watched $\mathrm{QR} /$ promotion and video advertisements, respectively. These results implied that the factors increasing the preference and those increasing the purchase intention are different. Regardless of types of advertising, it is important to produce immersive advertisements to enhance preference, and to provide more information needed and customized advertising messages to raise up purchase intention.
\end{abstract}

Keywords: Advertising Type, Advertising Trait, Advertising Attitude, Purchase Intention, Mobile Advertising

\section{Introduction}

Media users and general consumers have dramatically increased their exposure to mobile advertising since 2010 as a result of the explosive increase in mobile and smart media communication. In the past several years, most people have begun using smart phones and other mobile media. According to one statistical analysis, mobile media as represented by smart phones, have rapidly replaced other media, resulting in a majority $(67.2 \%)$ of Korean consumers thinking that a smartphone is their most essential device compared to any other media[1]. Also, $85 \%$ of Koreans first check their smart phones within 30 minutes after they wake up every morning. According to an experiment conducted by SalesBrain which was the first neuro-marketing company to use neuro-science to help corporations increase sales, subjects tend to focus more on mobile screen content and to have a more positive attitude toward it than that of TV screen content because a mobile screen can transmit and share messages more effectively, more successfully and with less efforts[2].

Received: February 15, 2021; 1st Review Result: March 31, 2021; 2nd Review Result: May 18, 2021 Accepted: June 30, 2021 
These phenomena led to an unprecedented mobile advertising market growth in Korea. The result of this rapid growth of mobile advertising is that on-line advertising revenue now accounts for half of total Korean domestic media advertising expenditures and has done so for the past several years. Since Internet advertising expenditure is not growing, mobile advertising itself is expected to occupy over $50 \%$ of the whole advertising market soon[3]. Along with this, mobile advertising formats, strategies, and content consistently evolve driven by the fast evolution of differentiated mobile technologies. These technological refinements include personal customization, the use of location-based appeals, the increased accessibility to fingertips for users without time and space limits, the universal availability of text, audio, and video options, and the increased interactivity options among customers, platforms, and advertisers[4].

The rapid growth of the mobile advertising market has naturally attracted a diverse range of academic studies. Early studies tried to understand the differing traits of mobile advertising media while more recent studies range from examining mobile media consumer behaviors to empirical testing the effects of mobile technology and advertising. Nevertheless, there remains an unsatisfactory number of studies on smart phone advertising processes and their effects to establish a complete theoretical framework. This new trend modification regarding smart phone advertising therefore requires a new and innovative paradigm of corporate communication behaviors and strategies. It also means that more systematic and exhaustive analyses concerning the consumer response to these diverse mobile formats and mobile advertising messages are now needed.

It is important to empirically explore how people respond to various traits of mobile advertising and its effects to their subsequent intention to purchase advertised products or services. Therefore, this study is aimed to analyze the effects of different types and traits of advertisements for a product sent to smartphones on users' advertising preference and purchase intention. To achieve the purpose, the researchers applied two relevant theoretical models by Davis' TAM (Technology Acceptance Model) and Ducoffe's attitude model toward web advertising. The specific analyses were conducted with the data collected from a series of experiments that explored subjects' responses to experimental treatments consisting of different types of mobile advertisements.

\section{Literature Review}

\subsection{Processes of Mobile Advertising Effects}

Mobile advertising research has flourished since the mid-2000s when mobile phone technology began advancing quickly. The main stream of this research included values of mobile advertising, the acceptance or rejection level of mobile advertising, and the process of its effects[5]. In practice, a majority of the studies focused on advertising effect processes.

Core theoretical bases describing and explaining the processes of mobile advertising effects included;

(1) Davis' technology acceptance model that examined how new technologies or new working tools were adopted and satisfied by their users, and

(2) Ducoffe's attitude model toward web advertising.

Davis' model emphasized new technology users' perceived usefulness and ease of use[6]. Ducoffe's model proposed that informativeness, entertainment, and irritation were key factors influencing advertising values and purchase intention[7]. These models have been developed after considering several more factors added from subsequent replication studies testing the validity of the original models. These included factors of credibility, personalization (customization), ubiquity, efficiency (economy), preference, and immersion. 


\subsection{The Types of Mobile Advertising and Their Effects}

In this study, two main factors have been suggested and explored for their contribution to mobile advertising effects. One of them is advertising type and the other is advertising attitude. The shape and characteristics of advertising have persistently changed in accordance with changes in the media environment and dominance. Advertising types on mobile media became more diverse than they were during previous mass media advertising. It is difficult to show all the individual types and forms of mobile advertising but it is possible to categorize them. Mobile advertising types include expression type(text, banner, audio/video), transmission type(push, pull), and message type(content, transaction, response, location, timing, and media-mix)[8]. However, in general they are perceived and categorized into two types which are format and content and these categories have been the ones used by prior studies. Formats of mobile advertising consist of shape, lay-out, and interactivity, while content of mobile advertising consists of product or service, theme, cognitive or affective, positive or negative, traits of models(celebrities), and so on.

An early study explored the differences between the effects of different mobile advertising types and content within the context of involvement and used passive learning theories. The results showed that image advertisements were more effective in inducing favorable attitude in consumers rather than the use of text advertisements in mobile communication situation. That study also found that consumers preferred giveaway advertisements to product advertisements because they were exposed to advertisements in a low-involvement situation[9]. A meta-analysis study showed that image or visual banner advertisements were more effective than text-alone banner advertisements. Also, interstitials or roll-over type advertisements were more effective than that of simple banner advertisement[10]. In addition, QR code advertising became popular for a variety of marketing strategies due to its efficiency, its targeting, its on and off line linkage, and the measuring of its marketing results[11].

\subsection{Advertising Perception and Attitude}

Advertising attitude refers to the consumer's learned tendency or orientation to consistently respond to advertising stimuli favorably or unfavorably after being exposed to an advertisement. Depending on type and perceived traits of an advertisement, consumers come to have certain attitude toward advertisements, products, and brands in a variety of perception and attitude dimensions. This attitude in turn affects the consumers' purchase intention[12]. In terms of advertising effects in reality, actual purchases of advertised products are the ultimate purpose of advertising strategies. The most frequently analyzed elements of perceived traits of advertising and consumer attitude in prior studies include; information, credibility, customization, situation, convenience, economy, interest (entertainment), experience, compensation, immersion, interaction, rejection, attention, and preference.

One empirical study examined the relationship between characteristics of mobile advertising and consumer satisfaction from mobile advertising. This was done using a technology acceptance model which proposed 7 attitude dimensions regarding perceived characteristics of mobile advertising; entertainment, incentive, informativeness, irritation, customization, security, and usefulness. Among them, informativeness and irritation were reported to affect directly satisfaction while the other dimensions proved to be indirectly effective and were moderated by user's sex and age[13]. Another relevant study showed that the perceived informativeness of mobile advertising had a positive impact on purchase intention[14]. In addition, a study on effects of immersion and intrusiveness of mobile advertising on advertising acceptance showed the result that entertainment, economy(efficiency), immersion, and intrusiveness were important variables that explain ad attitudes and further intentions to interact with other consumers[15]. 


\subsection{Theoretical Framework for Analysis}

To summarize literature and prior research findings, key factors contributing to advertising attitude and effects were suggested. These factors were;

(1) types of mobile advertising,

(2) perceived traits of advertising

(3) attitude toward advertising.

They might influence intent to purchase advertised products.

The following theoretical model was proposed based on the findings of prior studies shown above, and it was analyzed in this study ([Fig. 1]).

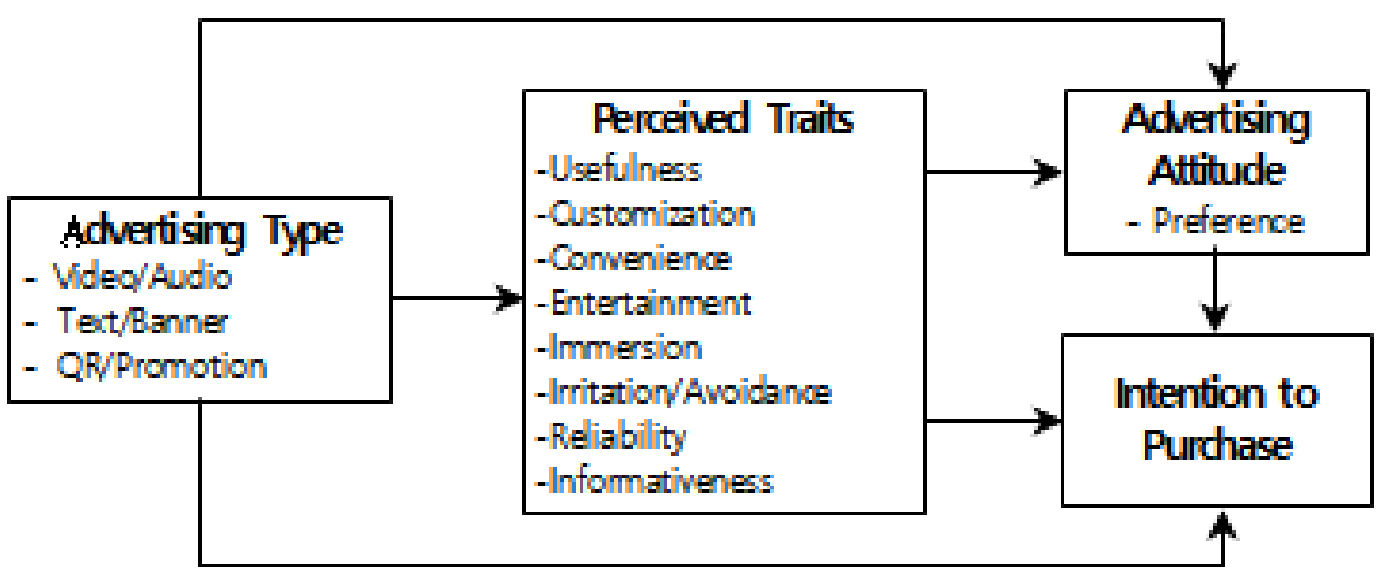

[Fig. 1] Smart Phone Advertising Effect Model for Analysis

\subsection{Research Question}

Based on the purpose of the study and the new theoretical framework, the following research questions are proposed.

RQ 1. How does exposure to different types of mobile advertising affect the perceived traits of mobile advertising and the advertising attitudes and effects?

RQ 2. What is the relationship between user's perception of mobile advertising and advertising attitudes and purchase intention when exposed to the same type of advertisements?

\section{Method}

A series of experiments were conducted on October 2020 to answer the research questions with 280 subjects and three different advertisements types for a single product.

\subsection{Experimental Treatments}

Three types of mobile advertisements promoting 'Jin Ramyeon', a Korean noodle product, were produced and edited into a suitable format for smart phones to show to the subjects as experimental treatments. The first type was three 15 -second video advertisements, the second were three text and banner advertisements that were linked to more specific information, and the third type was those that included QR codes and promotion messages ([Fig. 2]). 


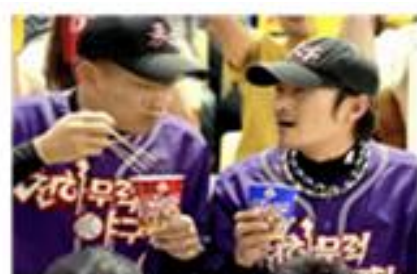

Video Treatment1

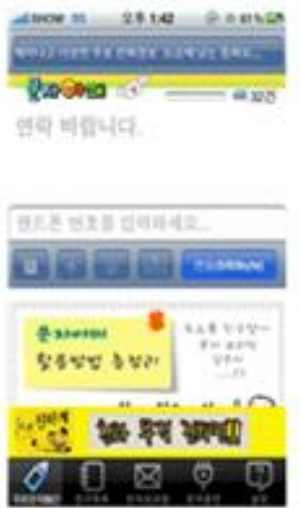

Text/Banner Treatment 1

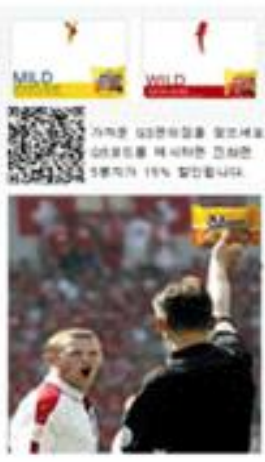

QR/Promotion Treatment1

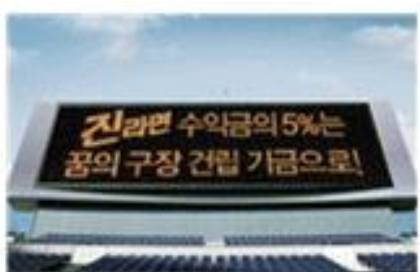

Video Treatment2

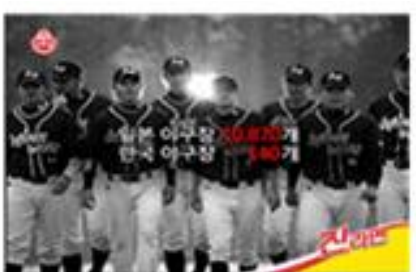

Video Treatment3

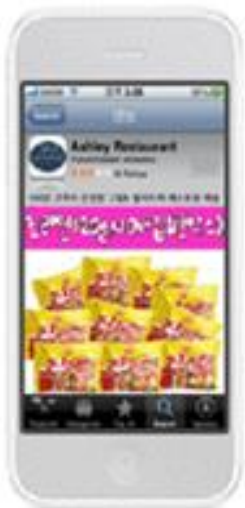

Text/Banner Treatment2

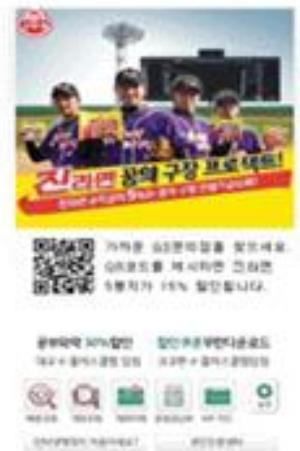

QR/Promotion Treatment1

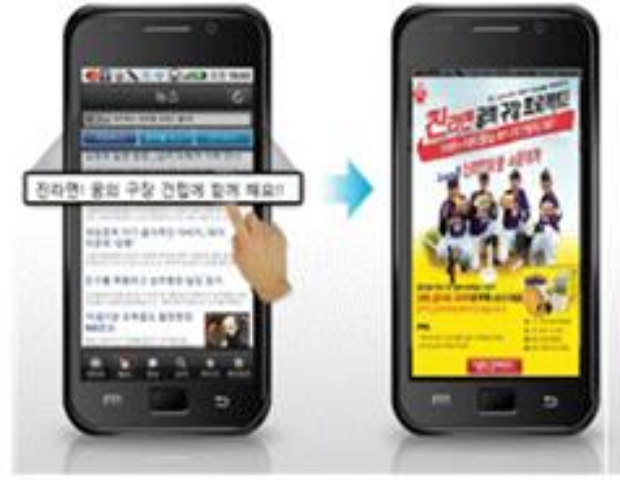

Text/Banner Treatment3

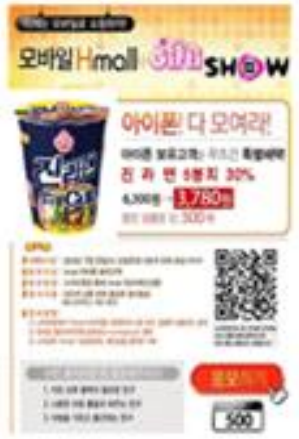

QR/Promotion Treatment1

[Fig. 2] Advertisements Used as Treatments

[Table 1] Subject and Groups for Experiment

\begin{tabular}{|c|c|c|c|c|c|}
\hline & Group I & Group II & Group III & Group IV \\
\hline \multicolumn{2}{|c|}{$\begin{array}{c}\text { Ad Type } \\
\text { (Treatment) }\end{array}$} & $\begin{array}{c}\text { None } \\
\text { (Control Group) }\end{array}$ & $\begin{array}{c}\text { Video } \\
\text { (Treatment G.) }\end{array}$ & $\begin{array}{l}\text { Text/Banner } \\
\text { (Treatment G.) }\end{array}$ & $\begin{array}{l}\text { QR/Promotion } \\
\text { (Treatment G.) }\end{array}$ \\
\hline \multicolumn{2}{|c|}{$\mathrm{N}=280$} & 70 & 70 & 70 & 70 \\
\hline \multirow{2}{*}{ Sex } & Male & $28(40 \%)$ & $28(40 \%)$ & $28(40 \%)$ & $28(40 \%)$ \\
\hline & Female & $42(60 \%)$ & $42(60 \%)$ & $42(60 \%)$ & $42(60 \%)$ \\
\hline \multicolumn{2}{|c|}{ Average Age } & 21.50 & 21.59 & 21.09 & 21.80 \\
\hline
\end{tabular}




\subsection{Subjects}

The study was conducted involving 280 college students in the Busan Area. The students were social science majors and were randomly selected and evenly allocated to 4 groups proportionately by controlling their sex (male 40\%, female 60\%) and age (between 21.09 and 21.80 years old). Out of the 4 groups, one group was chosen and functioned as the control group and was not exposed to any treatment message. Each of the other three groups was exposed to each of different treatment types (video, text/banner, QR/promotion) of advertisements ([Table 1]).

\subsection{Research Tool}

Each group of the subjects was asked to answer 10 categories of questions after contacting advertising messages two times. Eight categories asked questions about perceived traits of mobile advertisement they contacted (usefulness, customization, convenience, entertainment, immersion, irritation/avoidance, reliability, and informativeness). The other two categories asked the students about their preference for the advertisements and their purchase intention, respectively. Each category consisted of three questions with 7-point semantic differential scales. In order to attain reliability and validity of the questionnaire, two experts who are specialized in research methods and advertising practices carefully reviewed and validated the questions and the scales for measurement.

\subsection{Data Analysis}

Their answers were statistically analyzed using ANOVA (Analysis of Variance) to compare mean scores of three or more different groups, followed by Duncan mean comparison procedures designed to compare mean differences among groups with the same number of subjects. Also, multiple linear regression techniques were used to examine the linear relationships between predictors (independent variables) and criteria (dependent variables).

\section{Results}

To provide solutions to these research questions, a series of ANOVA were first conducted to compare mean scores among each group for perceived traits of advertising, advertising attitude, and purchase intention, and to testify the significance of the mean differences. To compare and testify specific mean differences among groups of the same size of samples, a Duncan Test was used. Secondly, a series of regression analyses were conducted to explore linear relations between perceived traits of advertising (independent variables), and advertising attitude and purchase intention (dependent variables) within each group of different advertising types.

The RQ 1. examined the relationship between exposure to different types of mobile advertising and perceived traits of mobile ads as well as advertising attitudes and effects ([Table 2]). The group exposed to text/banner advertising (TG) marked highest mean values in most aspects of perceived traits of mobile advertising except the 'irritation/avoidance' dimension. In contrast, the group exposed to video advertising (VG) marked the highest only in the 'irritation/avoidance dimension. The other groups (QG and CG) tended to mark their mean scores between TG and VG. These results imply the relatively high degree of persuasiveness and effectiveness of literal and specific content of advertising

[Table 3] shows the results of a series of regression analyses, giving answers to the RQ 2 . The table presents relationships among significant perceived advertising traits and advertising attitude (preference) and the effects within each experimental group. In terms of explaining and predicting the power of the 8 independent variables on the two dependent variables, the perceived traits show a larger 
combined predicting power on purchase intention than on preference. In general, the most influential factor on advertising attitude is 'immersion' in all the experimental groups. Purchase intention was affected most by 'informativeness' in all the groups except the $\mathrm{QR} /$ promotion group.

[Table 2] One-Way ANOVA: Mean Difference Test for Effects of Advertising Type (N=280)

\begin{tabular}{|c|c|c|c|c|}
\hline Groups & Control Group (CG) & Video Ad Group (VG) & $\begin{array}{c}\text { Text/Banner Group } \\
\text { (TG) }\end{array}$ & $\begin{array}{c}\text { QR/Promotion Group } \\
\text { (QG) }\end{array}$ \\
\hline (1) Usefulness & 3.76 & 3.57 & 4.47 & 3.71 \\
\hline F \& Duncan Test & \multicolumn{4}{|c|}{$\mathrm{F}=6.628^{* * *} ; \mathrm{TG}>\mathrm{CG}=\mathrm{QG}=\mathrm{VG}$} \\
\hline (2) Customization & 4.37 & 3.84 & 5.06 & 4.52 \\
\hline F \& Duncan Test & \multicolumn{4}{|c|}{$\mathrm{F}=9.120^{* * *} ; \mathrm{TG}>\mathrm{QG}=\mathrm{CG}>\mathrm{VG}$} \\
\hline (3) Convenience & 3.60 & 3.10 & 3.91 & 3.90 \\
\hline F \& Duncan Test & \multicolumn{4}{|c|}{$\mathrm{F}=5.714^{* *} ; \mathrm{TG}=\mathrm{QG}=\mathrm{CG}>\mathrm{VG}$} \\
\hline (4) Entertainment & 4.19 & 3.21 & 4.66 & 4.14 \\
\hline F \& Duncan Test & \multicolumn{4}{|c|}{$\mathrm{F}=10.729^{* * *} ; \mathrm{TG}=\mathrm{CG}=\mathrm{QG}>\mathrm{VG}$} \\
\hline (5) Immersion & 4.56 & 4.00 & 4.76 & 4.66 \\
\hline F \& Duncan Test & \multicolumn{4}{|c|}{$\mathrm{F}=4.243^{* *} ; \mathrm{TG}=\mathrm{QG}=\mathrm{CG}>\mathrm{VG}$} \\
\hline (6) Irritation/Avoidance & 4.74 & 4.99 & 3.80 & 4.23 \\
\hline F \& Duncan Test & \multicolumn{4}{|c|}{$\mathrm{F}=12.467 * * * ; \mathrm{VG}>\mathrm{CG}>\mathrm{TG}=\mathrm{QG}$} \\
\hline (7) Reliability & 3.94 & 3.73 & 4.50 & 3.84 \\
\hline F \& Duncan Test & \multicolumn{4}{|c|}{$\mathrm{F}=6.113 * * * ; \mathrm{TG}>\mathrm{CG}=\mathrm{QG}=\mathrm{VG}$} \\
\hline (8) Informativeness & 4.04 & 3.73 & 4.40 & 4.13 \\
\hline F \& Duncan Test & \multicolumn{4}{|c|}{$\mathrm{F}=4.382^{* *} ; \mathrm{TG}=\mathrm{QG}=\mathrm{CG}>\mathrm{VG}$} \\
\hline (9) Preference & 4.43 & 3.76 & 5.09 & 4.67 \\
\hline F \& Duncan Test & \multicolumn{4}{|c|}{$\mathrm{F}=11.179^{* * *} ; \mathrm{TG}>\mathrm{QG}=\mathrm{CG}>\mathrm{VG}$} \\
\hline (10) Purchase Intention & 4.11 & 3.67 & 4.73 & 4.20 \\
\hline F \& Duncan Test & \multicolumn{4}{|c|}{$\mathrm{F}=7.839 * * * ; \mathrm{TG}>\mathrm{QG}=\mathrm{CG}>\mathrm{VG}$} \\
\hline
\end{tabular}

[Table 3] Multiple Regression between Advertising Attitude by Group and Purchase Intention

\begin{tabular}{|c|c|c|c|c|c|c|c|c|c|c|}
\hline \multirow{2}{*}{$\begin{array}{l}\text { Experiment } \\
\text { Groups }\end{array}$} & \multirow{2}{*}{$\begin{array}{l}\text { Perceived Traits } \\
\text { (Significant } \\
\text { Variables Only) }\end{array}$} & \multicolumn{4}{|c|}{ Ad Attitude - Preference } & \multirow{2}{*}{$\begin{array}{c}\text { Perceived Traits } \\
\text { (Significant } \\
\text { Variables Only) }\end{array}$} & \multicolumn{4}{|c|}{ Ad Effects - Purchase Intention } \\
\hline & & $\beta$ & $\mathrm{t}$ & $\mathrm{p}$ & $\mathrm{R}^{2}$ & & $\beta$ & $\mathrm{t}$ & $\mathrm{p}$ & $\mathrm{R}^{2}$ \\
\hline $\begin{array}{l}\text { Control Group } \\
\qquad(\mathrm{N}=70)\end{array}$ & Customization & .322 & 2.022 & $.048^{*}$ & .253 & $\begin{array}{c}\text { Reliability } \\
\text { Informativeness }\end{array}$ & $\begin{array}{l}.339 \\
.289\end{array}$ & $\begin{array}{l}2.733 \\
2.237\end{array}$ & $\begin{array}{l}.008 * * \\
.029 *\end{array}$ & .518 \\
\hline $\begin{array}{l}\text { Video Group } \\
\qquad(\mathrm{N}=70)\end{array}$ & $\begin{array}{l}\text { Immersion } \\
\text { Reliability }\end{array}$ & $\begin{array}{l}.445 \\
.280\end{array}$ & $\begin{array}{l}2.916 \\
2.115\end{array}$ & $\begin{array}{l}.005^{* *} \\
.039 *\end{array}$ & .567 & $\begin{array}{l}\text { Convenience } \\
\text { Informativeness }\end{array}$ & $\begin{array}{l}.310 \\
.317\end{array}$ & $\begin{array}{l}2.981 \\
2.460\end{array}$ & $\begin{array}{l}.004 * * \\
.017 *\end{array}$ & .611 \\
\hline
\end{tabular}




\begin{tabular}{|c|c|c|c|c|c|c|c|c|c|c|}
\hline $\begin{array}{c}\text { Text/Banner Group } \\
(\mathrm{N}=70)\end{array}$ & $\begin{array}{c}\text { Customization } \\
\text { Immersion } \\
\text { Informativeness }\end{array}$ & $\begin{array}{c}.428 \\
.325\end{array}$ & $\begin{array}{c}3.059 \\
2.048\end{array}$ & $\begin{array}{c}.003^{* *} \\
.045^{*} \\
.001 * *\end{array}$ & .359 & Informativeness & .273 & 2.462 & $.017^{*}$ & .451 \\
\hline $\begin{array}{c}\text { QR/Promotion } \\
\text { Group (N=70) }\end{array}$ & Immersion & .575 & 3.107 & $.003^{* *}$ & .192 & Customization & .355 & 3.199 & $.002 * *$ & .584 \\
\hline$* \mathrm{p}<.05, * * \mathrm{p}<.01$
\end{tabular}

In the video, text/banner, and $\mathrm{QR} /$ promotion groups, preference for mobile advertisements increased when the advertisements were perceived as more immersive. Customization was a significant factor for advertising preference in both the control group and text/banner groups. Also, 'reliability' influenced the preference positively in the video group, and 'informativeness' was also a significant factor in the text/banner group. The most important contributing factor for purchase intention was 'informativeness' as many prior studies proved. It positively influenced purchase intention of subjects in the control, video, and text/banner groups similarly. In the QR/promotion group, 'customization' was the only significant factor for purchase intention. Also, 'reliability' was an important predictor in the control group and 'convenience' was important in the video group.

[Table 4] Relationship between Advertising Attitude and Purchase Intention (N=349)

\begin{tabular}{|c|c|c|c|c|c|}
\hline \multirow{2}{*}{ Groups } & \multicolumn{4}{|c|}{ Purchase Intention } \\
\cline { 2 - 6 } & Control & $\beta$ & $\mathrm{t}$ & $\mathrm{p}$ & $\mathrm{R}^{2}$ \\
\hline \multirow{3}{*}{$\begin{array}{c}\text { Ad Attitude } \\
\text { (Preference) }\end{array}$} & Video & .375 & 3.336 & $.001 * *$ & .141 \\
\cline { 2 - 6 } & Text/Banner & .447 & 4.123 & $.000^{* * *}$ & .200 \\
\cline { 2 - 6 } & QR/promotion & .550 & 5.425 & $.000^{* * *}$ & .302 \\
\cline { 2 - 6 } & & & & & \\
\end{tabular}

Additionally, the relationships between advertising attitude and its effect of each group were examined ([Table 4]). Partial correlation coefficients between the two, shown as $\beta \mathrm{s}$, ranged from .375 to .626 . The attitude occupied from $14.1 \%$ to $39.2 \%$ of the total variance $\left(\mathrm{R}^{2}\right)$ of purchase intention. They are proved very strongly related to each other at very low significance levels $(p<.01 ; p<.001)$.

\section{Conclusion}

This study intended to analyze the causal relationship among the types of the mobile advertisement, user's perception and attitude toward the advertising messages, and the user's subsequent intention to purchase. A series of experimental analyses were conducted using advertising treatments and four equivalent groups of college students. The research generated the following results and implications.

First, texts and banners advertisements with product and promotional information that are linked to more specific content are more effective in generating positive responses to most of the perceived traits of advertising. This finding seems to be related to one of other findings of this study that informativeness of advertisements was a core determinant of purchase intention.

Second, immersive video, text/banner, $\mathrm{QR} /$ promotion advertisements, and customized text/banner advertisements are all effective in effective for increasing advertising preference. This seems natural because most of the experimental groups, except for the control group which was not exposed to any 
advertisement, tended to concentrate on the advertising content. Also, this implies that advertising attitude normally could become positive when customers are exposed to and have a certain degree of involvement into mobile advertising messages seriously.

Third, informative video and text/banner advertisements, customized QR/promotion advertisements, and convenient video advertisements are effective in shaping purchase intention. This means that video and test/banner advertisements need to directly provide consumers with specific information on products or to give them convenient links to more specific and persuasive information in order to increase the purchase intention. In addition, QR/promotion advertisements need to propose customized information or interests suited for their target users.

Fourth, it was found that different types and traits of advertisements contributed to forming the advertising preference and purchase intention of the subjects. Throughout the most types of advertisements, immersion is a decisive factor for increasing preference while informativeness is the most important in forming the purchase intention. It implies that advertising practitioners need to have separate approaches to these two-step effects of advertising.

Finally, further research is needed to differentiate analysis with different advertised products. This study selected experimental treatments with a cheap product because the subjects were college students. In the present case of cheap food advertising, known independent variables are more likely to directly affect purchase intention than is advertising attitude according to the analyses in this study. The results could be different if the present study used experimental treatments of advertisements promoting products that needed higher involvement during purchasing processes such as more expensive or complex products. Therefore, various subjects and products need to be considered for the future experimental advertising research in order to enhance the generalization of research findings.

\section{References}

[1] Korean Communications Commission, Annual Research of Broadcast Media Usage Patterns, (2020)

[2] https://ko-kr.facebook.com/business/news/mobile-video-study-kr, Feb 25 (2021)

[3] https://adstat.kobaco.co.kr/sub/expenditure_data_search.do, Feb 15 (2021)

[4] S. H. Lee, The Research Trend and Theorizing of Mobile Advertising, Communication Theories, (2010), Vol.6, No.1, pp.6-49.

[5] J. S. Koo, J. H. Lee, W. S. Lee, Vitalization of Smart Phone Advertising Market in Media Convergence Environment, Korea Broadcast Advertising Commission, Seoul, Korea, (2010)

[6] F. Davis, V. Venhatesh, A Critical Assessment of Potential Measurement Biases in the Technology Acceptance Model: Three Experiments, International Journal of Man-Machine Studies, (1996), Vol.45, No.1, pp.19-45.

[7] R. H. Ducoffe, Advertising Value and Advertising on the Web, Journal of Advertising Research, (1996), Vol.36, No.5, pp.21-36.

[8] The Future of Wireless Marketing, Carat Interactive, Boston, MA, (2002)

[9] J. Y. Tak, Y. B. Hwang, An Exploratory Study on the Effects of Mobile Advertising: Focusing on the Involvement and Passive Learning Theories, Journal of Communication Science, (2005), Vol.5, No.1, pp.265-300.

[10] S. Lee, Y. Shon, A Study on the State and Trend of Internet Advertising and Mobile Advertising in Korea: A MetaAnalytic Review, The Korean Journal of Advertising, (2014), Vol.25, No.8, pp.179-211.

[11] https://www.mk.co.kr/news/economy/view/2011/01/23672/, Feb 28 (2021)

[12] J. S. Koo, J. H. Lee, W. S. Lee, Vitalization of Smart Phone Advertising Market in Media Convergence Environment, Korea Broadcast Advertising Commission, Seoul, Korea, (2010) 
[13] S. Kim, J. Yoon, Factors Affecting the Customer Satisfaction of Mobile Advertising: Focused on the Moderating Effect of Gender and Age, The Journal of Internet Electronic Commerce Research, (2015), Vol.15, No.4, pp.285-302.

[14] M. Choi, B. Lim, A Study on the Informativeness and the effect on the Purchase Intention based on types of Smart Phone Mobile Advertising, Asia-pacific Journal of Multimedia Services Convergent with Art, Humanities, and Sociology, (2017), Vol.7, No.7, pp.701-714.

[15] I. G. Shin, S. H. Choi, H. S. Shin, The Influences of Elements of the of the Interactions in Mobile Ads on the Their Acceptance: With the Absorption and Intrusiveness as the Mediating Variables, Journal of Korea Society of Design Forum, (2011), No.33, pp.299-308. 